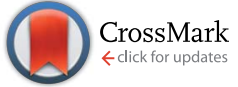

Cite this: RSC Adv., 2017, 7, 4320

\title{
Synthesis, mesomorphic and photophysical properties of novel triads and pentads of perylene liquid crystals with cholesterol units at the bay- position $\uparrow$
}

\begin{abstract}
Mingguang Zhu, ${ }^{a}$ Hongyu Guo, ${ }^{\star a}$ Fafu Yang ${ }^{* a b}$ and Zusheng Wang ${ }^{a}$
Series of triads and pentads of perylene derivatives with two cholesterol units at the bay-position or four cholesterol units on both bay-position and imide position were designed and synthesized in yields of 55-65\%. The influence of the different number and position of cholesterol substituents on mesomorphic properties and photophysical properties was studied. The results suggested that, in comparison with similar perylene derivatives with alkyl units at the imide position, the perylene liquid crystals with alkyl units at the bay-positions not only maintained excellent mesomorphic properties but also enhanced the fluorescence greatly. More cholesterol units resulted in a lower mesophase temperature, wider phase transfer temperature range, and higher fluorescence. A long spacer between perylene and cholesterol units led to more excellent mesomorphic properties and higher fluorescence.
\end{abstract}

Received 18th November 2016 Accepted 29th December 2016

DOI: $10.1039 / c 6 r a 27003 d$

www.rsc.org/advances

\section{Introduction}

During past decades, perylene bisimide (PBI) derivatives have been not only considered as important semiconductor materials with high electron affinity and strong fluorescence, ${ }^{1-6}$ but also recognized as excellent building platforms to construct well-defined supramolecular structures based on their unique $\pi-\pi$ stacking. ${ }^{7-9}$ Among all kinds of PBI aggregates, PBI liquid crystals (LC) have attracted much attention due to their excellent $\pi-\pi$ stacking properties for supramolecular selfassembling processes. ${ }^{\mathbf{1 0 , 1 1}}$ By modifying the imide groups with siloxane,$^{12,13}$ polyoxyethylene chain, ${ }^{14}$ fluoro-pentenyl groups, ${ }^{15}$ alkyl esters ${ }^{\mathbf{1 6}}$ organosilica, ${ }^{17}$ alkoxyl/alkyl groups, ${ }^{\mathbf{1 8 , 1 9}}$ dendritic peptides, ${ }^{20}$ phenyl substituents, ${ }^{21,22} 3,4,5$-trialkoxyphenyl, ${ }^{23,24}$ or triphenylene groups, ${ }^{25-27}$ different series of perylene columnar liquid crystals have been synthesized and their mesomorphic properties investigated. A survey of relevant literature implied that all perylene liquid crystals were prepared by modifying the two imide positions with two alkyl groups. Recently, we studied systematically perylene liquid crystals with two different baysubstituents and found that suitable substituents at the baypositions were favorable for the hexagonal columnar liquid crystalline phase and led to wider phase transfer temperature ranges. ${ }^{28}$ Inspired by this research, we are further interested in

\footnotetext{
${ }^{a}$ College of Chemistry and Chemical Engineering, Fujian Normal University, Fuzhou 350007, P. R. China.E-mail: yangfafu@fjnu.edu.cn

${ }^{b}$ Fujian Key Laboratory of Polymer Materials, Fuzhou 350007, P. R. China

$\dagger$ Electronic supplementary information (ESI) available: Materials, synthesis and characterisation of new compounds. See DOI: 10.1039/c6ra27003d
}

whether it is possible to construct perylene liquid crystals by introducing alkyl groups onto the bay-position or onto both the imide position and bay-position. Moreover, what is the influence of different numbers and substitution positions of the alkyl groups on the mesomorphic and photophysical properties? However, no paper has studied this so far.

Based on the above considerations, in the present research, series triads and pentads of perylene derivatives with two cholesterol units at the bay-position or four cholesterol units on both bay-position and imides position were purposely designed and synthesized. The detailed structures and synthetic routes of these compounds were exhibited in Scheme 1. Also, the influence of the different number and diverse position of alkyl substituents on mesomorphic properties and photophysical properties were firstly investigated. The results suggested that the perylene liquid crystals with cholesterol units at the bayposition not only maintained excellent mesomorphic properties but also enhanced greatly the fluorescence in solution. The more cholesterol units leaded to lower mesophase temperature, wider scopes of phase transfer temperatures, and higher fluorescence.

\section{Experimental}

\section{Instrumentation and methods}

The organic solvents were purified according to standard anhydrous methods before use. All other chemical reagents were used directly without further purification. TLC analysis was carried out by pre-coated glass plates. Column chromatography was performed by using silica gel (200-300 mesh) as 


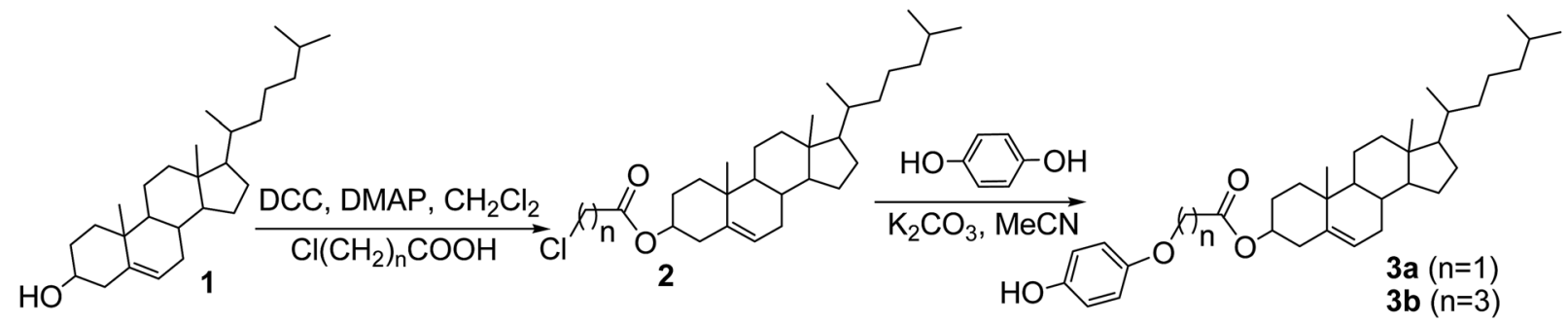

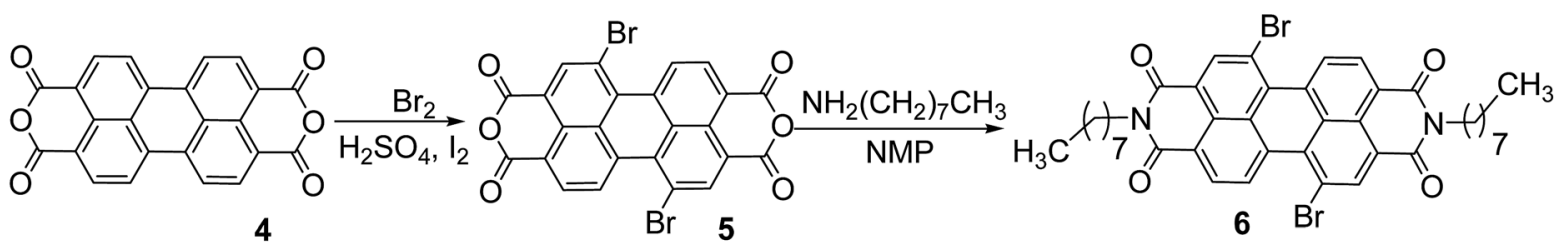

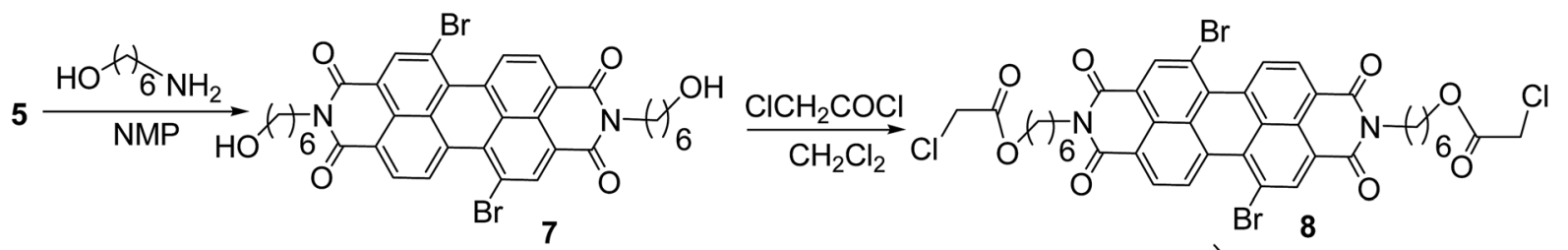

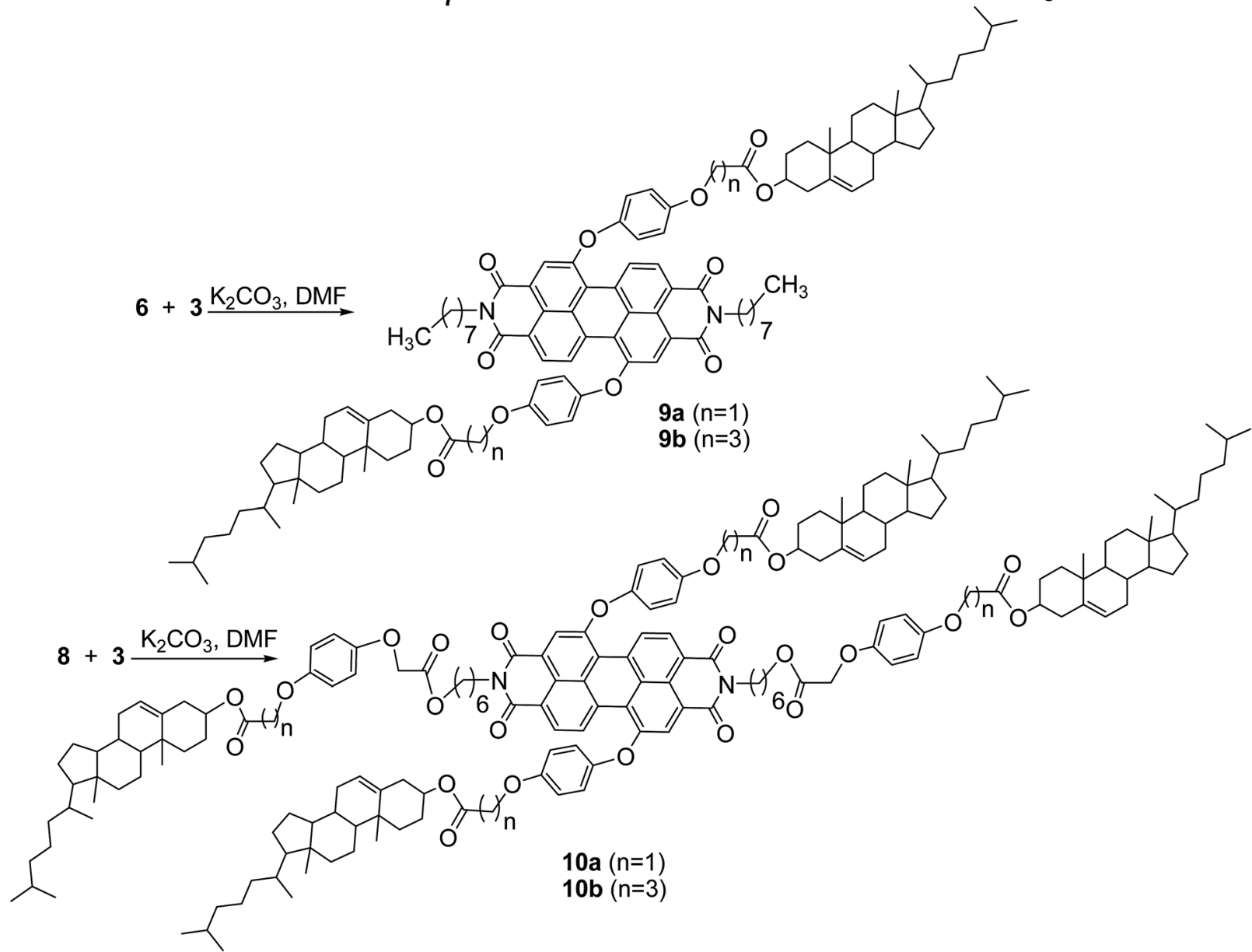

Scheme 1 The synthetic routes for perylene liquid crystals 9a, 9b, 10a and 10b.

absorbing column. All NMR spectra were done on a Bruker-ARX 400 instrument at $25{ }^{\circ} \mathrm{C}$, using tetramethylsilane (TMS) as internal standard. MS spectra were obtained on Bruker MALDI-
TOF mass spectrometer. UV-vis and fluorescence spectra were performed on Varian spectrometer. Fluorescence spectra were measured on a Hitachi F-4500 spectrometer equipped with 
excitation and emission slits $10 \mathrm{~nm}$ wide. The fluorescence absolute $\Phi_{\mathrm{F}}$ values were obtained on an Edinburgh Instruments FLS920 Fluorescence Spectrometer with a 6-inch integrating sphere. POM (Leica DMRX) was used with the help of a hot stage (Linkam THMSE 600) to examine phase transitions. Thermal analysis was performed by using DSC (Thermal Analysis Q100), with the scanning rate of $10{ }^{\circ} \mathrm{C} \min ^{-1}$ under $\mathrm{N}_{2}$ atmosphere. XRD experiments were done on SEIFERT-FPM (XRD7), using $\mathrm{Cu}$ $\mathrm{K} \alpha 1.5406 \AA$ as the radiation source with $40 \mathrm{kV}, 30 \mathrm{~mA}$ power. Compounds $\mathbf{2}$ and $\mathbf{5}$ were synthesized by the literature methods, ${ }^{29,30}$ respectively.

\section{Synthesis of compounds $3 a$ and $3 b$}

Under $\mathrm{N}_{2}$ atmosphere, the mixture of compound $2 \mathbf{a}$ or $2 \mathbf{b}$ (1 $\mathrm{mmol})$, hydroquinone $(0.55 \mathrm{~g}, 5 \mathrm{mmol})$ and $\mathrm{K}_{2} \mathrm{CO}_{3}(0.69 \mathrm{~g}, 5$ $\mathrm{mmol}$ ) was stirred in DMF $(50 \mathrm{~mL})$ at $110{ }^{\circ} \mathrm{C}$ for $20 \mathrm{~h}$. The reaction was monitored by TLC. After cooling, $40 \mathrm{~mL}$ of $\mathrm{HCl}$ solution ( $1 \mathrm{M}$ ) was added slowly in the reaction system, and the white precipitates appeared. Then the precipitates were filtered and purified by recrystallization with $\left(\mathrm{CH}_{2} \mathrm{Cl}_{2} / \mathrm{CH}_{3} \mathrm{OH}(1 / 1, \mathrm{v} / \mathrm{v})\right)$ for three times. The compound $\mathbf{3 a}$ and $\mathbf{3} \mathbf{b}$ were obtained as white solids. The yields were $63 \%$ and $67 \%$, respectively. Compound 3a: ${ }^{1} \mathrm{H}$ NMR (400 $\left.\mathrm{MHz}, \mathrm{CDCl}_{3}\right) \delta_{\mathrm{ppm}}: 0.68-2.35(\mathrm{~m}$, $43 \mathrm{H}$ of cholesterol), $4.55\left(\mathrm{~s}, 2 \mathrm{H}, \mathrm{OCH}_{2}\right), 4.76$ (bs, $1 \mathrm{H}, \mathrm{OCH}$ on cholesterol), $5.40(\mathrm{~s}, 1 \mathrm{H}, \mathrm{CH}=\mathrm{C}$ on cholesterol), $6.77(\mathrm{~d}, J=$ $8.0 \mathrm{~Hz}, 2 \mathrm{H}, \mathrm{ArH}), 6.82$ (d, $J=8.0 \mathrm{~Hz}, 2 \mathrm{H}, \mathrm{ArH}), 6.86$ (s, 1H, OH). Compound 3b: ${ }^{1} \mathrm{H}$ NMR $\left(400 \mathrm{MHz}, \mathrm{CDCl}_{3}\right) \delta_{\mathrm{ppm}}: 0.68-2.35(\mathrm{~m}$, $45 \mathrm{H}$ of cholesterol), $2.50\left(\mathrm{t}, 2 \mathrm{H}, J=7.6 \mathrm{~Hz}, \mathrm{CH}_{2} \mathrm{CO}\right), 3.51(\mathrm{t}, 2 \mathrm{H}, J$ $=7.6 \mathrm{~Hz}, \mathrm{OCH}_{2}$ ), 3.96 (bs, $1 \mathrm{H}, \mathrm{OCH}$ on cholesterol), 4.60 (bs, $1 \mathrm{H}, \mathrm{OH}), 5.38(\mathrm{~s}, 1 \mathrm{H}, \mathrm{CH}=\mathrm{C}$ on cholesterol), $6.76(\mathrm{~d}, J=8.0 \mathrm{~Hz}$, $2 \mathrm{H}, \mathrm{ArH}), 6.78$ (d, $J=8.0 \mathrm{~Hz}, 2 \mathrm{H}, \mathrm{ArH})$.

\section{Synthesis of compound 6}

Under $\mathrm{N}_{2}$ atmosphere, the mixture of 1,7-dibromoperylene tetracarboxylic anhydride $5(0.55 \mathrm{~g}, 1 \mathrm{mmol})$ and octylamine $(0.27 \mathrm{~g}, 2.1 \mathrm{mmol})$ was stirred in the solution of NMP $(50 \mathrm{~mL})$ at $80{ }^{\circ} \mathrm{C}$ for $10 \mathrm{~h}$. Then $50 \mathrm{~mL}$ of distilled water was poured in the reaction mixture. The obtained red precipitates were filtered and washed by $20 \mathrm{~mL}$ of methanol. The crude product was purified by column chromatography $\left(\mathrm{CH}_{2} \mathrm{Cl}_{2} /\right.$ ethyl acetate $(5 / 1$, $\mathrm{v} / \mathrm{v})$ ). The compound 6 were collected as red solid in yield of 86\%. Compound 6: ${ }^{1} \mathrm{H} \mathrm{NMR}\left(400 \mathrm{MHz}, \mathrm{CDCl}_{3}\right) \delta_{\mathrm{ppm}}: 9.34(\mathrm{~d}, J=$ $8.0 \mathrm{~Hz}, 2 \mathrm{H}, \mathrm{ArH}), 8.78$ (s, 2H, ArH), 8.57 (d, $J=8.0 \mathrm{~Hz}, 2 \mathrm{H}, \operatorname{ArH}$ ), $4.16\left(\mathrm{t}, J=8.0 \mathrm{~Hz}, 4 \mathrm{H}, \mathrm{NCH}_{2}\right), 1.73$ (bs, $\left.4 \mathrm{H}, \mathrm{CH}_{2}\right), 1.22-1.50(\mathrm{~m}$, $\left.20 \mathrm{H}, \mathrm{CH}_{2}\right), 0.88\left(\mathrm{t}, J=8.0 \mathrm{~Hz}, 6 \mathrm{H}, \mathrm{CH}_{3}\right)$; MALDI-TOF-MS $\left(\mathrm{C}_{40} \mathrm{H}_{40} \mathrm{Br}_{2} \mathrm{~N}_{2} \mathrm{O}_{4}\right)[\mathrm{M}]^{+}$: calcd: 772.1 . Found: 772.8 .

\section{Synthesis of compound 7}

Under $\mathrm{N}_{2}$ atmosphere, 1,7-dibromoperylene tetracarboxylic anhydride $(0.5 \mathrm{~g}, 0.9 \mathrm{mmol})$ was reacted with 6-amino-1-hexanol $(0.27 \mathrm{~g}, 2.3 \mathrm{mmol})$ in NMP $(15 \mathrm{~mL})$ at $95{ }^{\circ} \mathrm{C}$ for $6 \mathrm{~h}$. After reaction, $50 \mathrm{~mL}$ of distilled water was added in the solution, and the red precipitates were obtained. Then the red precipitates were separated out. The crude product was washed by $30 \mathrm{~mL}$ of methanol. The yield was $85 \%$. Because of the crude product had poor solubility in all kinds of solvents, the NMR spectrum was not done for the crude product, which was used directly for the next step without further purification. Compound 7: FT-IR(KBr), $\nu / \mathrm{cm}^{-1}$ : 3392, 2937, 1698, 1658, 1591, 1435, 1337, 1241, 1052, 808, 746. MALDI-TOF-MS: calculated for $\mathrm{C}_{36} \mathrm{H}_{32} \mathrm{Br}_{2} \mathrm{~N}_{2} \mathrm{O}_{6}$ $771.0503[\mathrm{M}]^{+}$; found: 771.0525 .

\section{Synthesis of compound 8}

Under $\mathrm{N}_{2}$ atmosphere, the mixture of compound 7 ( $0.38 \mathrm{~g}, 0.05$ $\mathrm{mmol})$ and chloracetyl chloride $(0.5 \mathrm{~mL})$ were stirred in $\mathrm{CH}_{2} \mathrm{Cl}_{2}$ $(10 \mathrm{~mL})$ at $35^{\circ} \mathrm{C}$ for $6 \mathrm{~h}$. TLC detection implied the disappearance of reactant. Then, $10 \mathrm{~mL}$ of distilled water was added and the organic layer was separated. The organic layer was washed by brine solution and dried over anhydrous $\mathrm{MgSO}_{4}$. The solution was concentrated and the residue was treated with $10 \mathrm{~mL}$ of $\mathrm{MeOH}$. The obtained red precipitate was collected and further purified by column chromatography $\left(\mathrm{CH}_{2} \mathrm{Cl}_{2} /\right.$ ethyl acetate $(10 /$ $1, \mathrm{v} / \mathrm{v}))$. The compound $\mathbf{8}$ were obtained as red solid in the yield of 75\%. Compound 8: ${ }^{1} \mathrm{H}$ NMR (400 $\left.\mathrm{MHz}, \mathrm{CDCl}_{3}\right) \delta_{\mathrm{ppm}}$ : $9.44(\mathrm{~d}, J=8.0 \mathrm{~Hz}, 2 \mathrm{H}, \operatorname{ArH}), 8.87(\mathrm{~s}, 2 \mathrm{H}, \operatorname{ArH}), 8.66(\mathrm{~d}, J=$ $8.0 \mathrm{~Hz}, 2 \mathrm{H}, \mathrm{ArH}), 4.16-4.22\left(\mathrm{~m}, 8 \mathrm{H}, \mathrm{OCH}_{2}\right.$ and $\left.\mathrm{NCH}_{2}\right), 4.06(\mathrm{~s}$, $4 \mathrm{H}, \mathrm{ClCH}_{2} \mathrm{CO}$ ), $1.40-1.80\left(\mathrm{~m}, 16 \mathrm{H}, \mathrm{CH}_{2}\right)$; MALDI-TOF-MS $\left(\mathrm{C}_{40^{-}}\right.$ $\left.\mathrm{H}_{34} \mathrm{Br}_{2} \mathrm{Cl}_{2} \mathrm{~N}_{2} \mathrm{O}_{8}\right)[\mathrm{M}]^{+}$: calcd: 900.0 . Found: 899.5.

\section{Synthesis of compounds $9 \mathrm{a}$ and $9 \mathrm{~b}$}

Under $\mathrm{N}_{2}$ atmosphere, the mixture of compound 6 ( $0.39 \mathrm{~g}, 0.5$ mmol), compound $3 \mathbf{a}$ or $3 \mathbf{b}(1.3 \mathrm{mmol})$, anhydrous $\mathrm{K}_{2} \mathrm{CO}_{3}$ $(0.18 \mathrm{~g}, 1.3 \mathrm{mmol})$ were stirred in $30 \mathrm{~mL}$ of $\mathrm{DMF}$ at $95{ }^{\circ} \mathrm{C}$ for $10 \mathrm{~h}$. The reaction process was detected by TLC till the disappearance of compound 6 . Then the solution was cooled to room temperature and $50 \mathrm{~mL}$ of $\mathrm{HCl}$ solution $(1 \mathrm{M})$ was added in it. The solution was extracted with $40 \mathrm{~mL}$ of $\mathrm{CHCl}_{3}$. The organic layer was partitioned, washed with brine solution and dried over anhydrous $\mathrm{MgSO}_{4}$. After filtration, the solution was concentrated and further purified by column chromatography $\left(\mathrm{CH}_{2} \mathrm{Cl}_{2}\right.$ /ethyl acetate $\left.(6 / 1, \mathrm{v} / \mathrm{v})\right)$. The compounds $9 \mathbf{a}$ and $\mathbf{9 b}$ were collected as red solids in the yields of $60 \%$ and $65 \%$, respectively. Compound 9a: ${ }^{1} \mathrm{H}$ NMR $\left(400 \mathrm{MHz}, \mathrm{CDCl}_{3}\right) \delta_{\mathrm{ppm}}: 9.60(\mathrm{~d}, J$ $=8.0 \mathrm{~Hz}, 2 \mathrm{H}, \operatorname{ArH}), 8.61(\mathrm{~d}, J=8.0 \mathrm{~Hz}, 2 \mathrm{H}, \operatorname{ArH}), 8.29(\mathrm{~s}, 2 \mathrm{H}$, $\operatorname{ArH}), 7.12$ (d, $J=8.0 \mathrm{~Hz}, 4 \mathrm{H}, \operatorname{ArH}), 7.01$ (d, $J=8.0 \mathrm{~Hz}, 4 \mathrm{H}, \operatorname{ArH}$ ), 5.40 (bs, 2H, C=CH), 4.77 (bs, $2 \mathrm{H}, \mathrm{OCH}), 4.63$ (s, $\left.4 \mathrm{H}, \mathrm{OCH}_{2} \mathrm{CO}\right)$, $4.13\left(\mathrm{t}, 4 \mathrm{H}, J=8.0 \mathrm{~Hz}, \mathrm{NCH}_{2}\right), 0.64-2.41\left(\mathrm{~m}, 116 \mathrm{H}, \mathrm{CH}, \mathrm{CH}_{2}\right.$ and $\left.\mathrm{CH}_{3}\right) ;{ }^{13} \mathrm{C} \mathrm{NMR}\left(100 \mathrm{MHz}, \mathrm{CDCl}_{3}\right) \delta_{\mathrm{ppm}}: 168.14,163.28,162.86$, $155.79,155.38,149.10,139.25,124.82,123.70,123.59,123.33$, 123.12, 123.04, 122.14, 121.04, 119.68, 116.73, 115.85, 75.41, $66.21,56.68,56.14,50.01,42.32,39.72,39.52,36.59,36.19$, $35.80,31.83,29.23,23.84,22.57,19.33,18.72,14.11,11.87$; MALDI-TOF-MS calcd for $\mathrm{m} / z=1684.1$, found: $\mathrm{m} / \mathrm{z}=1683.1$ $\left(\mathrm{M}^{-}\right)$. HR-MS (ESI) $\left(\mathrm{C}_{110} \mathrm{H}_{142} \mathrm{~N}_{2} \mathrm{O}_{12}\right)[\mathrm{M}]^{+}$: calcd: 1684.0591. Found: 1684.0636. Compound 9b: ${ }^{1} \mathrm{H}$ NMR (400 $\mathrm{MHz}, \mathrm{CDCl}_{3}$ ) $\delta_{\text {ppm: }} 9.63(\mathrm{~d}, J=8.0 \mathrm{~Hz}, 2 \mathrm{H}, \mathrm{ArH}), 8.61$ (d, $\left.J=8.0 \mathrm{~Hz}, 2 \mathrm{H}, \mathrm{ArH}\right)$, 8.29 (s, 2H, ArH), 7.11 (d, $J=8.0 \mathrm{~Hz}, 4 \mathrm{H}, \operatorname{ArH}), 6.98(\mathrm{~d}, J=$ $8.0 \mathrm{~Hz}, 4 \mathrm{H}, \mathrm{ArH}$ ), 5.38 (bs, 2H, C=CH), 4.65 (bs, 2H, OCH), 4.14 $\left(\mathrm{t}, 4 \mathrm{H}, J=7.2 \mathrm{~Hz}, \mathrm{NCH}_{2}\right), 4.05\left(\mathrm{t}, 4 \mathrm{H}, J=7.2 \mathrm{~Hz}, \mathrm{OCH}_{2}\right), 0.64-$ $2.57\left(\mathrm{~m}, 124 \mathrm{H}, \mathrm{CH}, \mathrm{CH}_{2}\right.$ and $\left.\mathrm{CH}_{3}\right) ;{ }^{13} \mathrm{C} \mathrm{NMR}\left(100 \mathrm{MHz}, \mathrm{CDCl}_{3}\right.$ ) $\delta_{\text {ppm: }} 172.57,163.37,162.99,157.20,156.42,148.24,139.72$, $133.51,130.03$, 1224.74, 124.51, 123.61, 123.21, 122.98, 122.71, 
121.26, 121.15, 116.31, 116.26, 74.23, 67.39, 56.59, 56.08, 50.03, $42.32,40.63,39.73,39.42,38.17,36.92,36.68,36.19,35.80$, $32.63,31.82,31.04,29.71,28.23,28.02,27.11,24.72,24.29$, 23.83, 22.57, 20.98, 19.27, 18.65, 14.10, 11.79; MALDI-TOF-MS calcd for $m / z=1740.1$, found: $m / z=1740.8\left(\mathrm{M}^{+}\right)$. HR-MS (ESI) $\left(\mathrm{C}_{114} \mathrm{H}_{150} \mathrm{~N}_{2} \mathrm{O}_{12}\right)[\mathrm{M}]^{+}$: calcd: 1740.1217 . Found: 1740.1227.

\section{Synthesis of compounds 10a and 10b}

Under $\mathrm{N}_{2}$ atmosphere, the mixture of compound $8(0.27 \mathrm{~g}, 0.3$ $\mathrm{mmol})$, compound $3 \mathbf{a}$ or $3 \mathbf{b}(1 \mathrm{mmol})$, anhydrous $\mathrm{K}_{2} \mathrm{CO}_{3}(0.21 \mathrm{~g}$, $1.5 \mathrm{mmol})$ was stirred in DMF $(30 \mathrm{~mL})$ at $105{ }^{\circ} \mathrm{C}$ for $20 \mathrm{~h}$. Then the solution was treated by the similar synthetic procedure of compound 9, and the products were purified by column chromatography $\left(\mathrm{CH}_{2} \mathrm{Cl}_{2}\right.$ /ethyl acetate $\left.(8 / 1, \mathrm{v} / \mathrm{v})\right)$. The compounds $10 \mathrm{a}$ and $10 \mathrm{~b}$ were collected as red solids in the yields of $55 \%$ and $58 \%$, respectively. Compound 10a: ${ }^{1} \mathrm{H}$ NMR (400 $\mathrm{MHz}, \mathrm{CDCl}_{3}$ ) $\delta_{\text {ppm: }} 9.55(\mathrm{~d}, J=8.0 \mathrm{~Hz}, 2 \mathrm{H}, \operatorname{ArH}), 8.55$ (d, $\left.J=8.0 \mathrm{~Hz}, 2 \mathrm{H}, \operatorname{ArH}\right)$, 8.23 (s, 2H, ArH), 7.09 (d, $J=8.0 \mathrm{~Hz}, 4 \mathrm{H}, \operatorname{ArH}), 6.98$ (d, $J=$ $8.0 \mathrm{~Hz}, 4 \mathrm{H}, \mathrm{ArH}), 6.80$ (s, 8H, ArH), 5.39 (bs, $2 \mathrm{H}, \mathrm{C}=\mathrm{CH}), 5.34$ (bs, $2 \mathrm{H}, \mathrm{C}=\mathrm{CH}), 4.83$ (bs, $4 \mathrm{H}, \mathrm{OCH}), 4.63\left(\mathrm{~s}, 4 \mathrm{H}, \mathrm{OCH}_{2} \mathrm{CO}\right), 4.55$ (s, $\left.4 \mathrm{H}, \mathrm{OCH}_{2} \mathrm{CO}\right), 4.50$ (s, $\left.4 \mathrm{H}, \mathrm{OCH}_{2} \mathrm{CO}\right), 4.06-4.19$ (m, 8H, $\mathrm{OCH}_{2}$ and $\left.\mathrm{NCH}_{2}\right), 0.64-2.47\left(\mathrm{~m}, 188 \mathrm{H}, \mathrm{CH}, \mathrm{CH}_{2}\right.$ and $\left.\mathrm{CH}_{3}\right) ;{ }^{13} \mathrm{C} \mathrm{NMR}$ $\left(100 \mathrm{MHz}, \mathrm{CDCl}_{3}\right) \delta_{\mathrm{ppm}}: 169.19,168.45,168.13,162.94,162.61$, 159.08, 155.74, 154.52, 152.61, 139.24, 133.50, 133.32, 131.98, $130.47,130.15,128.87,124.86,124.76,123.13,123.00,122.15$, $121.74,121.05,116.73,116.07,115.87,115.78,75.40,75.03$, $71.88,66.28,66.19,65.27,56.54,56.05,49.86,42.43,39.66$, $39.43,37.95,36.88,36.54,36.27,35.86,31.85,29.71,28.24$, $27.93,27.73,26.56,25.52,24.17,23.85,22.77,22.50,20.90$, 19.41, 18.72, 11.97; MALDI-TOF-MS calcd for $m / z=2812.7$, found: $m / z=2812.3\left(\mathrm{M}^{+}\right)$. HR-MS (ESI) $\left(\mathrm{C}_{180} \mathrm{H}_{238} \mathrm{~N}_{2} \mathrm{O}_{24}\right)[\mathrm{M}]^{+}$: calcd: 2813.7526. Found: 2813.7513. Compound 10b: ${ }^{1} \mathrm{H}$ NMR $\left(400 \mathrm{MHz}, \mathrm{CDCl}_{3}\right) \delta_{\mathrm{ppm}}: 9.64(\mathrm{~d}, J=8.0 \mathrm{~Hz}, 2 \mathrm{H}, \mathrm{ArH}), 8.61(\mathrm{~d}, J=$ $8.0 \mathrm{~Hz}, 2 \mathrm{H}, \mathrm{ArH}), 8.29$ (s, 2H, ArH), 7.11 (d, $J=8.4 \mathrm{~Hz}, 4 \mathrm{H}, \mathrm{ArH}$ ), $6.98(\mathrm{~d}, J=8.4 \mathrm{~Hz}, 4 \mathrm{H}, \mathrm{ArH}), 6.80$ (s, 8H, ArH), 5.37 (bs, $4 \mathrm{H}, \mathrm{C}=$ $\mathrm{CH}$ ), 4.64 (bs, $4 \mathrm{H}, \mathrm{OCH}), 4.12-4.19\left(\mathrm{~m}, 8 \mathrm{H}, \mathrm{OCH}_{2} \mathrm{CO}\right.$ and $\left.\mathrm{ArOCH}_{2}\right), 4.02-4.08\left(\mathrm{~m}, 8 \mathrm{H}, \mathrm{OCH}_{2}\right), 3.94(\mathrm{t}, J=7.2 \mathrm{~Hz}, 4 \mathrm{H}$, $\left.\mathrm{NCH}_{2}\right), 0.62-2.59\left(\mathrm{~m}, 204 \mathrm{H}, \mathrm{CH}, \mathrm{CH}_{2}\right.$ and $\left.\mathrm{CH}_{3}\right) ;{ }^{13} \mathrm{C} \mathrm{NMR}(100$ $\left.\mathrm{MHz}, \mathrm{CDCl}_{3}\right) \delta_{\mathrm{ppm}}: 169.19,168.53,168.23,163.26,162.85$, 159.03 , 155.93, 154.58, 152.68, 139.28, 133.60, 132.02, 130.50, 128.92, 124.86, 123.71, 123.13, 123.00, 122.15, 121.74, 121.05, 116.73, 116.10, 115.87, 115.78, 75.53, 75.03, 71.76, 66.33, 66.03, $65.20,56.54,56.02,49.99,42.43,40.40,39.71,39.58,38.00$, $36.91,35.80,31.91,31.85,29.71,28.38,28.24,28.03,27.73$, $27.66,26.69,25.57,24.29,23.85,22.84,22.50,21.05,19.33$, 18.72, 11.87; MALDI-TOF-MS calcd for $m / z=2926.0$, found: $\mathrm{m} / \mathrm{z}$ $=2925.0\left(\mathrm{M}^{+}\right)$. HR-MS (ESI) $\left(\mathrm{C}_{188} \mathrm{H}_{254} \mathrm{~N}_{2} \mathrm{O}_{24}\right)[\mathrm{M}]^{+}$: calcd: 2925.8778. Found: 2925.8809.

\section{Results and discussion}

\section{Synthesis and characterization}

The previous reports had shown that the four bay-substituents on perylene derivatives might destroy the $\pi-\pi$ stacking of perylene core and resulted in no liquid crystalline behaviors due to the strong steric hindrance. ${ }^{31-33}$ However, two bay-substituents might be favorable for the wide scopes of phase transfer temperatures. ${ }^{28,31-33}$ Thus, the 1,7-bay-substituted perylene derivative 5 was chosen as building platform to construct the triads and pentads of perylene with multi-cholesterol units. The synthetic routes were illustrated in Scheme 1. Firstly, by esterifying reaction with chlorinated carboxylic acid and subsequently etherifying reaction with excess $p$-benzenediol, cholesterol was conveniently transferred to cholesterol derivatives $\mathbf{3 a}$ and $\mathbf{3 b}$ with terminal phenolic hydroxyl group, which easily react with halogen group on perylene. In this reaction, two and four carbon atom chains for chlorinated carboxylic acid were used to investigate the influence of chain length on mesomorphic and photophysical property. On the other hand, the 1,7-dibrominated perylene bisanhydrides 5 was prepared by the previous literature. ${ }^{30}$ By ammonolysis procedure of compound 5 with $n$-octylamine or 6-amino-1-hexanol, the corresponding perylene bisimides 6 and 7 with two halogen groups were obtained in yields of $85 \%$ and $86 \%$, respectively. Furthermore, compound 7 was reacted with chloroacetyl chloride to afford perylene imides 8 containing four halogen groups in yield of $75 \%$. Due to the poor dissolubility, compounds 5 and 7 was not purified and used directly in next step. Compounds 6 and 8 were purified by column chromatography and some byproducts in the previous steps, such as the complicated isomers in bromination reaction, were separated out. The pure compounds 6 and 8 were obtained in ideal yields of $75 \%$ and $85 \%$, respectively. Finally, by treating compound $3 \mathrm{a}(\mathbf{b})$ with perylene imides 6 or 8 in $\mathrm{K}_{2} \mathrm{CO}_{3} / \mathrm{DMF}$ system, the triads $\mathbf{9 a}(\mathbf{b})$ with two cholesterol units at the bay-position, and the pentads $10 a(b)$ with four cholesterol units on both bay-position and imides position were prepared in yields of 55-65\% after column chromatography, respectively.

All new compounds were characterized by ${ }^{1} \mathrm{H}$ NMR, ${ }^{13} \mathrm{C}$ NMR, MALDI-TOF-MS and HR-MS spectral analysis. Their mass spectrometry spectra showed corresponding molecular ion peaks for $\mathrm{M}^{+}$or $\mathrm{MNa}^{+}$. The deviations of HR-MS were less than $5 \mathrm{ppm}$. In the ${ }^{1} \mathrm{H}$ NMR spectra, all protonic signals were well assigned for the corresponding structures (see ESI $\dagger$ ). Especially, the protons of perylene core of compounds $\mathbf{9}$ and $\mathbf{1 0}$ showed two symmetrical doublets and one singlet, suggesting the 1,7-baypositions of perylene skeleton. The signals of ${ }^{13} \mathrm{C}$ NMR also supported the 1,7-bay-substituents structures with two singlets for $\mathrm{C}=\mathrm{O}$ of imides. These data implied that the small quantities of isomers or by-products (such as 1,6-dibrominated isomer in preparing for compound 5) were removed completely by column chromatography. All these characteristic data were in accordance with the proposed structures of target compounds $\mathbf{9 a}, \mathbf{9 b}$, 10a and 10b. Although compounds 5 and 7 showed the poor dissolubility, the target perylene derivatives exhibited excellent dissolubility in common organic solvents such as $\mathrm{CH}_{2} \mathrm{Cl}_{2}$, $\mathrm{CHCl}_{3}$, toluene, THF and DMF.

\section{Mesomorphic properties}

Compounds 9a, 9b, 10a and 10b were studied preliminarily by differential scanning calorimeter (DSC) to investigate their phase transition behaviours. Compound $\mathbf{1 1}$ with two 


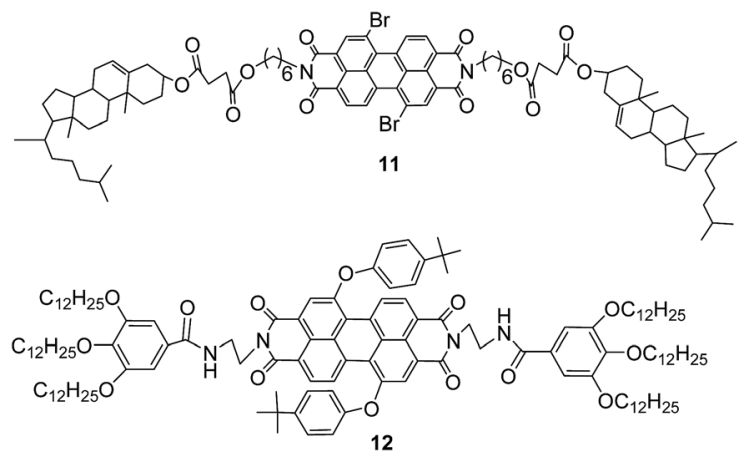

Fig. 1 The reference compounds 11 and 12 for comparison.

cholesterol units on imides position and compound $\mathbf{1 2}$ with similar perylene core were used as reference compounds for the comparison (Fig. 1). ${ }^{28,34}$ The DSC curves of compounds $9 \mathbf{9 a}, \mathbf{9 b}$, 10a and 10b for second heating and cooling were illustrated in Fig. 2. The phase transition temperatures and enthalpy changes for these compounds were summarized in Table 1. It can be seen that all of new perylene derivatives possessed two phase transition peaks on second heating at $32-61{ }^{\circ} \mathrm{C}$ and $162-234^{\circ} \mathrm{C}$, respectively. Upon cooling, two corresponding exothermic peaks appeared at $28-58^{\circ} \mathrm{C}$ and $154-215^{\circ} \mathrm{C}$, respectively. These data indicated they had good reversible phase transition behaviours at similar temperatures on heating and cooling. Based on these data, it was reasonable to deduce the transition of crystal phase-mesophase-isotropic phase for the phase transition process. The slightly hysteresis phenomena could be attributed to the super-cooling behaviours for such viscous materials. Thus, these DSC curves suggested that compounds 9a, 9b, 10a and 10b were perylene liquid crystals with low mesomorphic temperatures and wide scopes of mesophase.

Moreover, in comparison with compound 11 containing two cholesterol units on imides position, compounds $\mathbf{9 a}$ and $\mathbf{9 b}$ with two cholesterol units on bay-positions, in which two phenyls on bay-positions enlarged the areas of $\pi-\pi$ stacking of rigid perylene core, still showed the low mesomorphic temperatures, although these temperatures were higher little

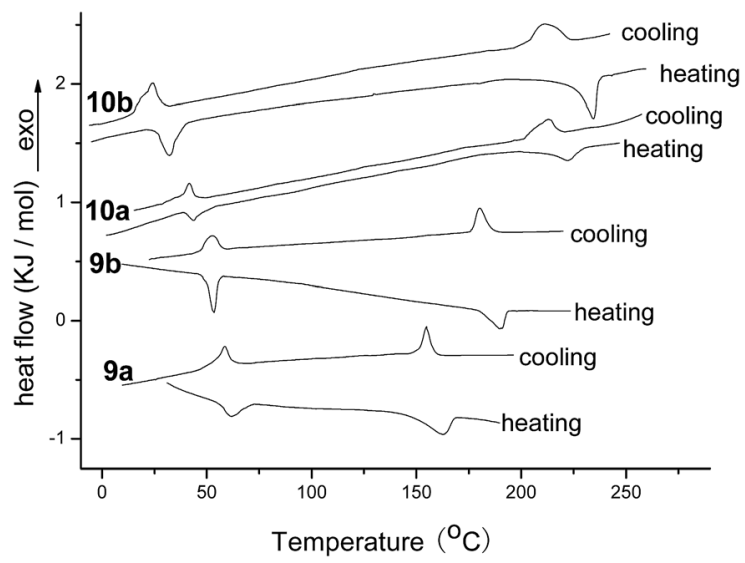

Fig. 2 The DSC traces of compounds $9 a, 9 b, 10 a$ and $10 b$ on second heating and cooling (scan rate $10^{\circ} \mathrm{C} \mathrm{min}^{-1}$ ). than that of compound 11. Also, by comparing with compound 12 possessing similar perylene core, compounds $9 \mathbf{a}$ and $\mathbf{9 b}$ exhibited similar mesomorphic temperatures at about $60{ }^{\circ} \mathrm{C}$. These results suggested that the perylene liquid crystals with cholesterol units at the bay-position maintained the excellent mesomorphic properties as the similar perylene liquid crystal with alkyl units at the imide positions. On the other hand, compounds 10a and 10b with four cholesterol units on both bay-position and imides position showed lower mesomorphic temperatures and wider scopes of mesophase than that of compounds 9a, 9b, 11, and $\mathbf{1 2}$ with two alkyl units on imides or bay-position. Especially, the mesomorphic temperature of compound $10 \mathrm{~b}$ was as low as $32{ }^{\circ} \mathrm{C}$ and the scope of mesophase was as wide as $202{ }^{\circ} \mathrm{C}$ after calculation, which was seldom observed for perylene liquid crystals. As to the influences of different spacers between perylene and cholesterol moieties, compounds $\mathbf{9 b}$ and $\mathbf{1 0 b}$ derived from chlorobutyric acid exhibited lower mesomorphic temperatures and wider scopes of mesophase than compounds 9a and 10a derived from chloroacetic acid, indicating that the long spacer was favorable for good mesomorphic property. Based on these DSC analyses, it could be concluded that triads $9 \mathbf{a}$ and $\mathbf{9 b}$, and pentads $10 \mathbf{a}$ and 10b were excellent perylene liquid crystals with low mesomorphic temperatures and wide scopes of mesophase. The perylene liquid crystals with alkyl units on bay-position possessed good mesomorphic properties as the analogous perylene liquid crystals with alkyl units at the imides position. The more cholesterol units in perylene liquid crystals leaded to the lower mesophase temperature and the wider scopes of phase transfer temperatures. The longer spacer also resulted in the lower mesophase temperature and the wider scopes of mesophase.

Polarizing optical microscopy (POM) was then employed to study the mesophase of compounds $9 \mathbf{9 a}, \mathbf{9 b}, \mathbf{1 0 a}$ and $\mathbf{1 0 b}$. At the approximate temperatures of phase transition in DSC curves, the phase transfer behaviours of $\mathrm{Cr}-\mathrm{Col}$ and Col-Iso phase were observed for compounds $\mathbf{9 a}, \mathbf{9 b}, \mathbf{1 0 a}$ and $\mathbf{1 0 b}$. After being heated to isotropic phase, they were cooled slowly to mesophase and the columnar textures appeared gradually. Fig. 3 illustrated their mesomorphic textures at $130^{\circ} \mathrm{C}$. All of them exhibited the

Table 1 Transition temperatures $\left({ }^{\circ} \mathrm{C}\right)$ and enthalpy changes $\left(\mathrm{kJ} \mathrm{mol}^{-1}\right)$ of compounds $9 \mathrm{a}, 9 \mathrm{~b}, 10 \mathrm{a}$ and $10 \mathrm{~b}$

\begin{tabular}{llll}
\hline Compd & Phase transition $^{a}$ & Heating scan $T(\Delta H)$ & Cooling scan $T(\Delta H)$ \\
\hline $\mathbf{9 a}$ & Cr-Col & $61.8(10.6)$ & $58.5(8.5)$ \\
& Col-Iso & $162.9(13.8)$ & $154.8(9.9)$ \\
$\mathbf{9 b}$ & Cr-Col & $53.3(12.2)$ & $52.1(8.9)$ \\
& Col-Iso & $190.5(11.1)$ & $180.1(10.4)$ \\
$\mathbf{1 0 a}$ & Cr-Col & $43.6(12.4)$ & $41.5(10.6)$ \\
& LC-Iso & $222.1(19.3)$ & $212.9(22.3)$ \\
$\mathbf{1 0 b}$ & Cr-Col & $32.4(16.6)$ & $23.9(18.1)$ \\
& Col-Iso & $234.3(23.8)$ & $210.8(21.9)$ \\
$\mathbf{1 1}^{b}$ & Cr-Col & $34.9(20.1)$ & $32.6(13.9)$ \\
& Col-Iso & $197.7(16.3)$ & $180.4(8.8)$ \\
$\mathbf{1 2}^{c}$ & Cr-Col & $61.7(14.89)$ & $59.3(13.02)$ \\
& Col-Iso & $247.9(19.34)$ & $239.6(18.68)$
\end{tabular}

${ }^{a} \mathrm{Cr}=$ crystalline, $\mathrm{Col}=$ columnar mesophase, Iso $=$ isotropic. ${ }^{b}$ These data were cited from ref. $34{ }^{c}$ These data were cited from ref. 28. 
pseudo-confocal conic textures which were typical columnar textures, indicating they were columnar liquid crystals.

As the liquid crystalline phase were confirmed by DSC and POM, compounds 9a, 9b, 10a and $10 b$ were further examined by X-ray diffraction (XRD) to study their molecular stacking behaviors in mesophase. Fig. 4 illustrated their XRD traces at $130^{\circ} \mathrm{C}$ for the mesophase. In the small angle region, three peaks at $2.55^{\circ}, 4.43^{\circ}$ and $5.15^{\circ}$ for $9 \mathrm{a}, 2.42^{\circ}, 4.23^{\circ}$ and $4.86^{\circ}$ for $9 \mathrm{~b}$, $2.15^{\circ}, 3.73^{\circ}$ and $4.36^{\circ}$ for $10 \mathrm{a}, 2.05^{\circ}, 3.58^{\circ}$ and $4.12^{\circ}$ for $10 \mathrm{~b}$ were observed obviously, respectively. Based on Bragg equation, the d-spacing could be calculated by formula $d=\lambda /(2 \sin \theta)$. The calculating results for these reflections were $34.61 \AA$, $19.93 \AA$ and $17.15 \AA$ for $9 a, 36.47 \AA, 20.87 \AA$ and $18.18 \AA$ for $9 \mathbf{b}, 41.05 \AA$, $23.67 \AA$ and $20.25 \AA$ for 10a, $43.06 \AA, 24.66 \AA$ and $21.48 \AA$ for $10 \mathrm{~b}$, respectively. These distances were in agreement with the ratios of $1: 1 / \sqrt{ } 3: 1 / \sqrt{ } 4$ for (100), (110) and (200) reflections, which were the typical reflection mode for the hexagonal columnar liquid crystals. Furthermore, in the wide angle region, the broad halos between $15^{\circ}$ and $30^{\circ}$, indicating the mean distance of 4.5 $\AA$ approximately, could be assigned for the reflections of very short correlation length of the molten alkyl chains. Moreover, a small reflection at $22.43^{\circ}, 23.19^{\circ}, 22.10^{\circ}$, and $23.35^{\circ}$ could be distinguished for compounds 9a, 9b, 10a and 10b, respectively. These peaks implied the spacing of $3.96 \AA$, $3.83 \AA$, 4.01, and 3.97 $\AA$, respectively. These spacings were in accordance with the typical characteristic of $\pi-\pi$ interaction for the intracolumnar distance of ordered hexagonal columnar liquid crystals. Moreover, based on the above analysis, the calculated lattice parameter $\alpha$ for compounds 9a, 9b, 10a and $\mathbf{1 0 b}$ was $39.86 \AA$, $41.74 \AA$, $47.34 \AA$ and $49.32 \AA$, respectively. These data were $30 \%$ less than the diameters of compounds $\mathbf{9}(\sim 60 \AA)$ and $\mathbf{1 0}(\sim 80 \AA)$ simulated by CPK molecular model. These results suggested that the flexible alkyl chains of these perylene derivatives might be curled and fold or interdigitated in liquid crystalline phase. On the other hand, the average number $(n)$ of molecules in one single disk of the column could be calculated according to the following formula. ${ }^{35,36}$

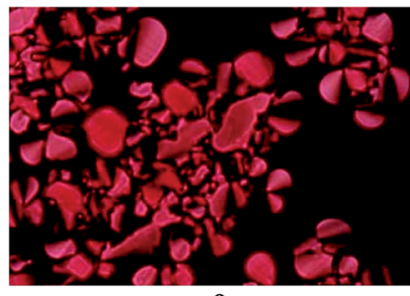

$9 \mathbf{a}$

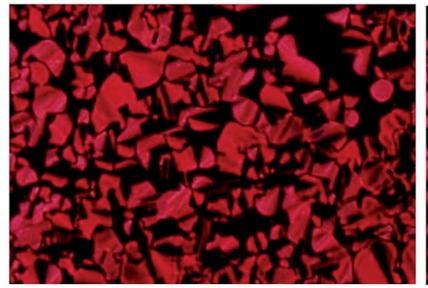

$10 \mathrm{a}$
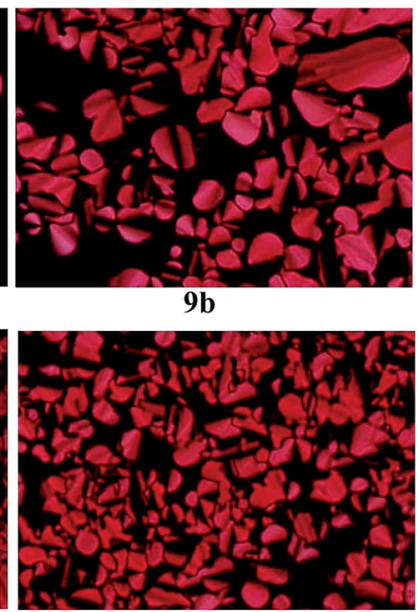

$10 \mathrm{~b}$
Fig. 3 The textures of compounds $9 a, 9 b, 10 a$ and $10 b$ obtained with POM on cooling at $130{ }^{\circ} \mathrm{C}(\times 400)$.

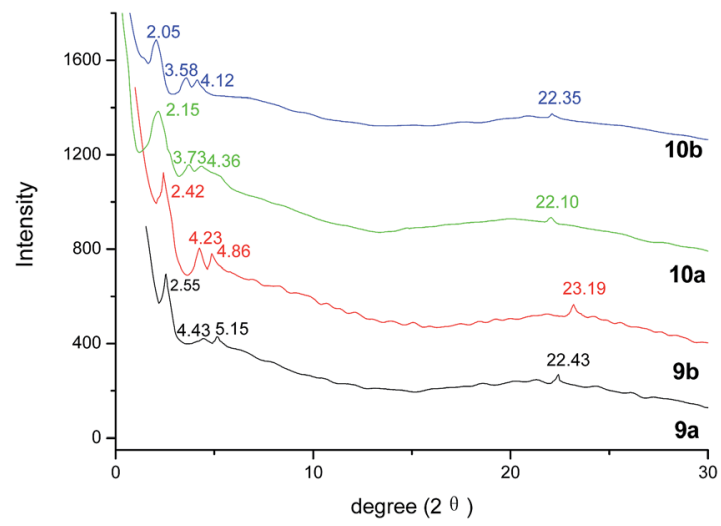

Fig. 4 XRD traces of compounds 9a, 9b, 10a and 10b measured at $130^{\circ} \mathrm{C}$.

$$
n=\left(\alpha^{2}\right)(\sqrt{ } 3 / 2)\left(h \rho N_{\mathrm{A}} / M\right)
$$

where the notation " $\alpha$ " is the hexagonal lattice parameter, $N_{\mathrm{A}}$ is Avogadro's number, $M$ is the molecular mass of the compound and the density $(\rho)$ of these compounds is assumed as $1 \mathrm{~g}$ $\mathrm{cm}^{-3}{ }^{35,36}$ After calculation, the number of molecules $(n)$ per slice was approximately 2 for compounds 9a, 9b, 10a and $10 b$. Thus, the possible arrangement for the molecular stacking of hexagonal columns of compounds $9 a, 9 b, 10 a$ and $10 b$ were proposed as shown Fig. 5. All these XRD analyses suggested that triads $9 \mathbf{a}$ and $9 \mathbf{b}$, and pentads $10 \mathrm{a}$ and $10 \mathbf{b}$ were hexagonal columnar liquid crystals, indicating the alkyl units on bayposition or on both bay-position and imides position of perylene derivatives were favorable for the formation of hexagonal columnar liquid crystals.

\section{Photophysical properties}

The excellent photophysical property is the important characteristic of perylene derivatives. In order to study the influence of

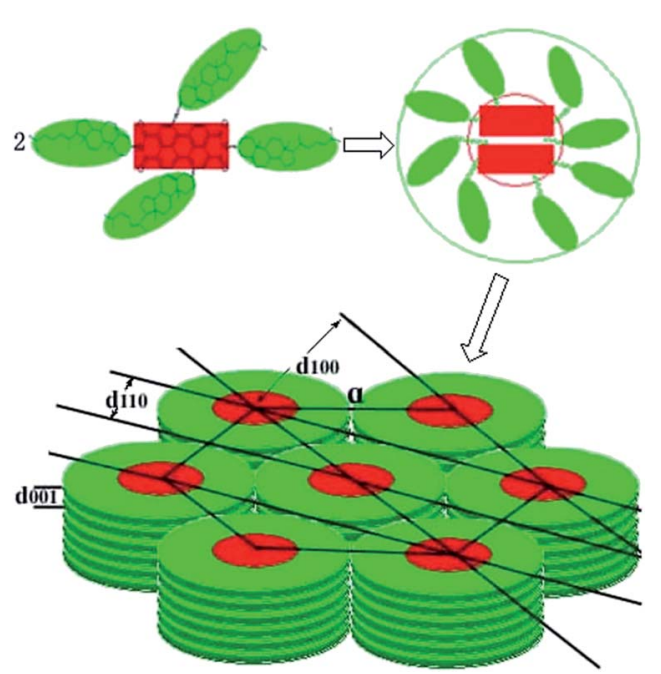

Fig. 5 The proposed molecular stacking of hexagonal columns of compounds 9a, 9b, 10a and 10b 
the different number and position of alkyl substituents on photophysical properties, the absorption spectra and fluorescence spectra of compounds 9a, 9b, 10a and $10 b$ were investigated and compared with that of reference compounds $\mathbf{1 1}$ and 12. Firstly, the solvent effect for absorption spectrum and fluorescence spectrum were studied in different solvents. They showed similar change in the tested solvents. The representative spectra of compound $\mathbf{1 2}$ were illustrated in Fig. S25 and S26. $\uparrow$ The maximal absorption wavelength changed obviously between $450 \mathrm{~nm}$ and $600 \mathrm{~nm}$ with different absorbance. The particularly red-shifted spectra of $\mathbf{1 2}$ in polar solvents could be attributed to the lower excited state energy of $\pi-\pi^{*}$ transition in polar solvents. The emission wavelengths of fluorescence spectra in different solvents were similar but the strongest fluorescence emission appeared in toluene solution. Therefore, toluene was used as solvent for the investigation of the absorption spectra and fluorescence spectra of compounds 9a, 9b, 10a and 10b. The results were shown in Fig. 6 and 7. Their corresponding spectral data were listed in Table 2. Comparing with compound 11, compounds 9a, 9b, 10a and 10b showed red shifts for the wavelength of absorption and fluorescence spectra. These phenomena could be attributed to the electronic effect of phenolic groups on bay-position, which enlarged the aromatic conjugated system of perylene core. However, although compounds $9 \mathbf{9 a}, \mathbf{9 b}, \mathbf{1 0 a}$ and $\mathbf{1 0 b}$ possessed the similar aromatic conjugated system of perylene core with compound 12, the wavelength of absorption and fluorescence spectra of compounds 9a, 9b, 10a and 10b presented obviously blue shifts. These results could be explained by that the bulky cholesterol units on bay-position of compounds 9a, 9b, 10a and 10b produced the strong steric hindrance and restrained the conjugates between phenolic group and perylene core.

Moreover, it can be seen that the fluorescence intensities of compounds 9a, 9b, 10a and 10b were far higher than that of compounds 11 and 12. The fluorescence quantum yields increased dramatically from 0.37 and 0.58 for compounds 11 and $\mathbf{1 2}$ to $0.93-0.96$ for compounds $9 \mathrm{a}, \mathbf{9 b}, \mathbf{1 0 a}$ and $\mathbf{1 0 b}$. These phenomena might be ascribed to two influencing factors. One

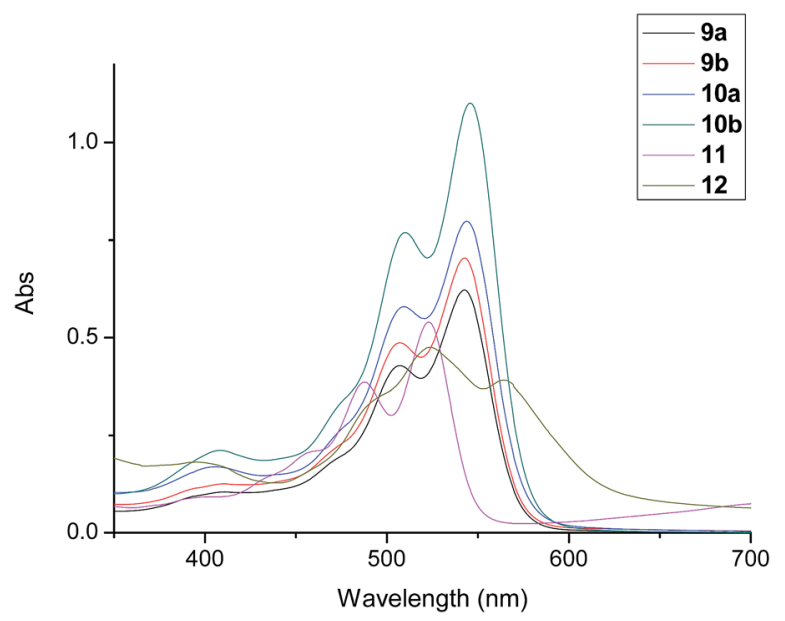

Fig. 6 Absorption spectra of compounds 9a, 9b, 10a and 10d, and reference compounds 11 and $12\left(10^{-5} \mathrm{M}\right)$.

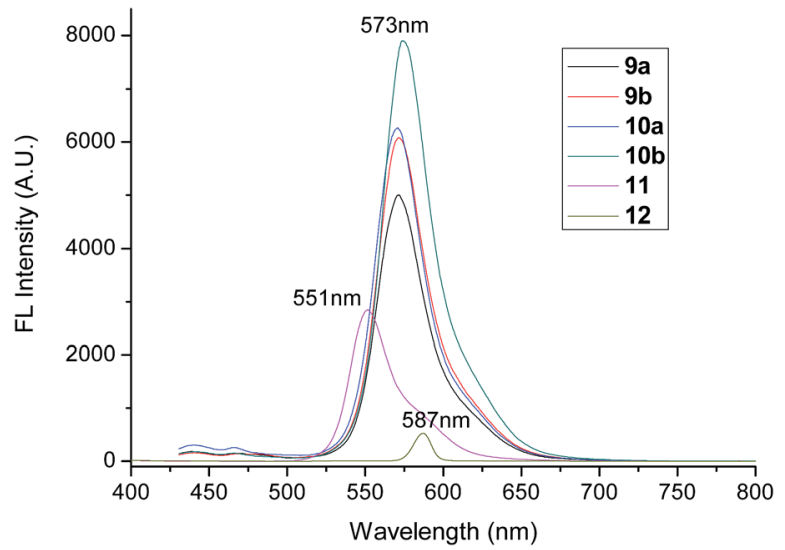

Fig. 7 Fluorescence emission spectra of compounds 9a, 9b, 10a and $10 \mathrm{~b}$ in toluene $\left(10^{-5} \mathrm{M}\right)$. The excitation wavelength was $518 \mathrm{~nm}$. The excitation wavelength of reference compounds 11 and 12 were $520 \mathrm{~nm}$ and $523 \mathrm{~nm}$, respectively.

was that the big alkyl units on bay-position enhanced the rotation limitation of phenolic group, resulting in the less energy-consuming and stronger fluorescence. These restricted intramolecular rotation mechanism was popular for explanation the fluorescence-enhancing in the field of aggregationinduced luminescence. ${ }^{37-39}$ Another factor was that the more alkyl units produced the stronger steric hindrances, which leaded to the reduction of the orderly aggregates in solution and then resulted in the enhancement of fluorescence intensity. On the other hand, compounds $\mathbf{9 b}$ and $\mathbf{1 0 b}$ derived from chlorobutyric acid showed stronger fluorescence than compounds 9a and 10a derived from chloroacetic acid, indicating the long soft spacer was favorable for the fluorescence. Especially, the fluorescence intensity of pentad $\mathbf{1 0 b}$ with four cholesterol units on both bay-position and imides position of perylene enhanced greatly and the fluorescence quantum yield reached as high as 0.96 , which were very outstanding among all kinds of perylene liquid crystals. ${ }^{14-28}$ The fluorescence of solid films for these perylene derivatives were also studied but little fluorescence was detected, suggesting that the orderly aggregates in solid state resulted in strong aggregation-caused quenching. These phenomena were similar with reference compounds $\mathbf{1 1}$ and $\mathbf{1 2}$, and commonly observed for perylene derivatives. Based on the above spectral analysis, it could be concluded that the perylene

Table 2 Absorption and fluorescence data for the compounds 9a, 9b, $10 \mathrm{a}$ and $10 \mathrm{~b}$ in toluene at $298 \mathrm{~K}$

\begin{tabular}{lllll}
\hline Comp. & $\lambda_{\text {abs }} / \mathrm{nm}$ & $\lambda_{\text {em }} / \mathrm{nm}$ & Stokes shift $/ \mathrm{nm}$ & $\Phi_{\mathrm{F}}$ \\
\hline $\mathbf{9 a}$ & 507,543 & 571 & 28 & 0.94 \\
$\mathbf{9 b}$ & 508,543 & 572 & 29 & 0.95 \\
$\mathbf{1 0 a}$ & 508,543 & 570 & 27 & 0.93 \\
$\mathbf{1 0 b}$ & 509,544 & 572 & 28 & 0.96 \\
$\mathbf{1 1}^{a}$ & 487,523 & 551 & 28 & 0.58 \\
$\mathbf{1 2}^{a}$ & 523,564 & 587 & 17 & 0.37
\end{tabular}

${ }^{a}$ The data of compounds $\mathbf{1 1}$ and $\mathbf{1 2}$ were cited from ref. 28 and 34, respectively. 
triads 9a and 9b with two cholesterol units at the bay-position, pentads 10a and 10b with four cholesterol units on both bayposition and imides position possessed more excellent fluorescence than the similar perylene derivatives with alkyl units on imides position. The alkyl units at the bay-positions enhanced greatly the fluorescence. The more alkyl units leaded to the higher fluorescence in solution.

\section{Conclusions}

In summary, the design and synthesis of the triads $\mathbf{9 a}$ and $\mathbf{9 b}$, pentads 10a and 10b based on perylene with two cholesterol units at the bay-position or four cholesterol units on both bayposition and imides position were reported in yields of 55$65 \%$. Their mesomorphic properties and photophysical properties were studied by DSC, POM, XRD, absorption spectra and fluorescence spectra. The results suggested that the different number and position of cholesterol substituents influenced remarkably on mesomorphic properties and photophysical properties. In comparison with the similar perylene derivatives with alkyl units on imides position, the perylene liquid crystals with alkyl units on bay-position not only maintained excellent mesomorphic properties but also enhanced greatly the fluorescence. The more cholesterol units resulted in the lower mesophase temperature, the wider scopes of phase transfer temperatures, and higher fluorescence. The long soft spacer between perylene and cholesterol units was favorable for excellent mesomorphic properties and high fluorescence.

\section{Acknowledgements}

Financial support from the National Natural Science Foundation of China (No: 21406036), Fujian Natural Science Foundation of China (No. 2014J01034) and the Program for Innovative Research Team in Science and Technology in Fujian Province Universit were greatly acknowledged.

\section{Notes and references}

1 C. W. Struijk, A. B. Sieval, J. E. J. Dakhorst, M. Dijk, P. Kimkes, R. B. M. Koehorst, H. Donker, T. J. Schaafsma, S. J. Picken, A. M. van de Craats, J. M. Warman, H. Zuilhof and E. J. R. Sudholter, J. Am. Chem. Soc., 2000, 122, 1105711066.

2 Y. V. Zatsikha, V. P. Yakubovskyi, M. P. Shandura and Y. P. Kovtun, Dyes Pigm., 2015, 114, 215-221.

3 L. Schmidt-Mende, A. Fechtenkötter, K. Müllen, E. Moons, R. H. Friend and J. D. MacKenzie, Science, 2001, 293, 11191122.

4 Y. P. Yu, F. Yang, Y. J. Ji, Y. G. Wu, A. D. Zhang, C. Li and W. W. Li, J. Mater. Chem. C, 2016, 4, 4134-4137.

5 I. Meazzini, N. Willis-Fox, C. Blayo, J. Arlt, S. Clément and R. C. Evans, J. Mater. Chem. C, 2016, 4, 4049-4059.

6 F. Galeotti, W. Mróz, M. Catellani, B. Kutrzeba-Kotowska and E. Kozma, J. Mater. Chem. C, 2016, 4, 5407-5415.

7 Y. K. Che, A. Datar, K. Balakrishnan and L. Zang, J. Am. Chem. Soc., 2007, 129, 7234-7235.
8 K. Sugiyasu, N. Fujita and S. Shinkai, Angew. Chem., 2004, 116, 1249-1253.

9 M. R. Islam and P. R. Sundararajan, Phys. Chem. Chem. Phys., 2013, 15, 21058-21069.

10 F. J. M. Hoeben, P. Jonkheijm, E. W. Meijer and A. P. Schenning, Chem. Rev., 2005, 105, 1491-1546.

11 T. Kato, N. Mizoshita and K. Kishimoto, Angew. Chem., Int. Ed., 2006, 45, 38-68.

12 T. J. Zhang, D. M. Sun, X. K. Ren, L. L. Liu, G. Y. Wen, Z. J. Ren, H. H. Li and S. K. Yan, Soft Matter, 2013, 9, 10739-10745.

13 M. Funahashi and A. Sonoda, Dalton Trans., 2013, 42, 1598715992.

14 R. A. Cormier and B. A. Gregg, Chem. Mater., 1998, 10, 13091315.

15 E. Wolarz, E. Mykowska, T. Martynski and R. Stolarski, J. Mol. Struct., 2009, 929, 79-84.

16 L. Wang, Q. Cui, X. F. Chen, Y. Li, Z. Q. Li, D. Wang and H. Yang, Aust. J. Chem., 2013, 66, 692-700.

17 N. Mizoshita, T. Tani and S. Inagaki, Adv. Funct. Mater., 2011, 21, 3291-3298.

18 B. A. Gregg and R. A. Cormier, J. Am. Chem. Soc., 2001, 123, 7959-7960.

19 Y. Xu, S. Leng, C. Xue, R. Sun, J. Pan, J. Ford and S. Jin, Angew. Chem., Int. Ed., 2007, 46, 3896-3899.

20 B. X. Gao, D. F. Xia, L. C. Zhang, Q. Q. Bai, L. B. Bai, T. Yang and X. W. Ba, J. Mater. Chem., 2011, 21, 15975-15982.

21 Z. An, J. Yu, S. C. Jones, S. Barlow, S. Yoo, B. Domercq, P. Prins, L. D. A. Siebbeles, B. Kippelen and S. R. Marder, Adv. Mater., 2005, 17, 2580-2581.

22 Z. Chen, U. Baumeister, C. Tschierske and F. Würthner, Chem.-Eur. J., 2007, 13, 450-465.

23 L. Meng, Q. M. Wu, F. F. Yang and H. Y. Guo, New J. Chem., 2015, 39, 72-76.

24 G. A. Bhavsar and S. K. Asha, Chem.-Eur. J., 2011, 17, 1264612658.

25 M. Bagui, T. Dutta, H. Z. Zhong, S. H. Li, S. Chakraborty, A. Keightley and Z. H. Peng, Tetrahedron, 2012, 68, 28062818.

26 S. K. Gupta, S. Setia, S. Sidiq, M. Gupta, S. Kumar and S. K. Pal, RSC Adv., 2013, 3, 12060-12065.

27 X. F. Kong, Z. Q. He, Y. N. Zhang, L. P. Mu, C. J. Liang, B. Chen, X. P. Jing and A. N. Cammidge, Org. Lett., 2011, 13, 764-767.

28 M. G. Zhu, H. Y. Guo, F. F. Yang and Z. S. Wang, Dyes Pigm., 2016, 133, 387-394.

29 H. Y. Guo, F. F. Yang, W. W. Liu and J. B. Lai, Tetrahedron Lett., 2015, 56, 866-870.

30 F. Würthner, V. Stepanenko, Z. Chen, C. R. Saha-Möller, N. Kocher and D. Stalke, J. Org. Chem., 2004, 69, 7933-7939.

31 Z. Chen, U. Baumeister, C. Tschierske and F. Würthner, Chem.-Eur. J., 2007, 13, 450-465.

32 F. Fennel, S. Wolter, A. Q. Xie, P. A. Plötz, O. Kühn, F. Würthner and S. Lochbrunner, J. Am. Chem. Soc., 2013, 135, 18722-18725.

33 F. Würthner, C. Thalacker, S. Diele and C. Tschierske, Chem.-Eur. J., 2001, 7, 224522-224553. 
34 M. G. Zhu, H. Y. Guo, F. F. Yang and Z. S. Wang, Liq. Cryst., 2016, 43, 1875-1883.

35 R. B. Hou, K. L. Zhong, Z. G. Huang, L. Y. Jin and B. Z. Yin, Tetrahedron, 2001, 67, 1238-1244.

36 S. Dattaa and S. Bhattacharya, Soft Matter, 2015, 11, 19451963.
37 Y. Hong, J. W. Y. Lam and B. Z. Tang, Chem. Soc. Rev., 2011, 40, 5361-5388.

38 M. Wang, G. Zhang, D. Zhang, D. Zhu and B. Z. Tang, J. Mater. Chem., 2010, 20, 1858-1867.

39 Y. Hong, J. W. Y. Lam and B. Z. Tang, Chem. Commun., 2009, 28, 4332-4335. 